\title{
Guideline adherence among prehospital emergency nurses when caring for patients with chest pain: a prospective cohort study
}

\author{
Kristoffer Wibring ${ }^{1,2^{*}}$ (D), Markus Lingman ${ }^{3,4}$, Johan Herlitz ${ }^{5}$ Lina Blom ${ }^{6}$, Otto Serholt Gripestam ${ }^{6}$ and \\ Angela Bång ${ }^{2}$
}

\begin{abstract}
Background: The emergency medical services (EMS) use guidelines to describe optimal patient care for a wide range of clinical conditions and symptoms. The intent is to guide personnel to provide patient care in line with best practice. The aim of this study is to describe adherence to such guidelines among prehospital emergency nurses (PENs) when caring for patients with chest pain.
\end{abstract}

Objective: To describe guideline adherence among PENs when caring for patients with chest pain. To investigate whether guideline adherence is associated with patient age, sex or final diagnosis of acute myocardial infarction on hospital discharge.

Methods: Guideline adherence in terms of patient examination and pharmaceutical treatment was analysed in a cohort of 2092 EMS missions carried out in 2018 in Region Halland, Sweden. Multivariate regression was used to describe how guideline adherence is associated with patient age, sex and diagnosis on hospital discharge.

Results: Guideline adherence was high regarding examination of vital signs (93\%) and electrocardiogram (ECG) registration (96\%) but lower in terms of pharmaceutical treatment (ranging from 28 to 90\%). Adherence was increased in cases in which the patient ended up with acute myocardial infarction (AMI) as diagnosis on discharge. Patients with AMI were given acetylsalicylic acid by PENs in 50\% of cases. Women were less likely than men to receive treatment with acetylsalicylic acid and oxycodone.

Conclusions: Guideline adherence among PENs when caring for patients with chest pain is satisfactory in terms vital signs and ECG registration. Regarding pharmaceutical treatment guideline adherence is defective. Improved adherence is mainly associated with male sex in patients and a diagnosis of AMI on hospital discharge. Defective adherence excludes measures known to improve patients' prognoses such as treatment with acetylsalicylic acid.

Keywords: Chest pain, Emergency medical services, Acute myocardial infarction, Guideline adherence, Guideline compliance

${ }^{*}$ Correspondence: kristoffer.wibring@gu.se

1 Department of Ambulance and Prehospital Care, Region Halland, Varlabergsvägen 29, 43439 Kungsbacka, Sweden

Full list of author information is available at the end of the article

\section{Background}

Chest pain is one of the most common complaints when contacting the emergency medical services (EMS). About $10-15 \%$ of all patient-related EMS missions concern patients with chest pain $[1,2]$ out of which about $10 \%$ have an acute myocardial infarction (AMI) $[3,4]$. original author(s) and the source, provide a link to the Creative Commons licence, and indicate if changes were made. The images or other third party material in this article are included in the article's Creative Commons licence, unless indicated otherwise in a credit line to the material. If material is not included in the article's Creative Commons licence and your intended use is not permitted by statutory regulation or exceeds the permitted use, you will need to obtain permission directly from the copyright holder. To view a copy of this licence, visit http://creativecommons.org/licenses/by/4.0/. The Creative Commons Public Domain Dedication waiver (http://creativeco mmons.org/publicdomain/zero/1.0/) applies to the data made available in this article, unless otherwise stated in a credit line to the data. 
The prehospital care of patients with acute non-traumatic chest pain is well established. It includes examination of vital signs and ECG registration, treatment with acetylsalicylic acid, glyceryl trinitrate and morphine [5]. If ST-elevation is present on the ECG, appropriate reperfusion should be initiated with minimal delay [6].

The EMS use guidelines to describe optimal patient care for a wide range of clinical conditions and symptoms, including chest pain. The intent is to guide EMS personnel to provide patient care in line with best practice [7]. However, guideline adherence among prehospital personnel varies widely between different studies and organisations [7-10]. In general, guideline adherence is reported to be fairly low [7-10]. Unsatisfactory guideline adherence deprives patients of best practice care and may result in avoidable morbidity or even death.

The poor guideline compliance in previous studies is partly explained by medication contraindications such as allergies or patients' previous medical history. However, this only explains a small proportion of cases of noncompliance [8]. Instead, low adherence is mainly explained either by the EMS personnel's assessment of chest pain as non-cardiac $[9,11]$ or of a patient's condition as being low priority [9].

This study describes chest pain guideline adherence among prehospital emergency nurses (PENs) and whether adherence varies depending on patient sex, age or prevalence of AMI.

\section{Objective}

- To describe guideline adherence among prehospital emergency nurses when caring for patients with chest pain.

- To investigate whether guideline adherence is associated with patient age, sex or final diagnosis of AMI on hospital discharge.

\section{Methods}

The study is part of the BRIAN research programme ((BRöstsmärta I AmbulaNs (Swedish), EMS Chest pain (English)). The BRIAN programme is mainly focused on prehospital assessment of patients with chest pain. Study population, data collection and clinical setting have been previously described and are therefore summarised briefly [4].

\section{Hypothesis}

The hypothesis was that adherence to guidelines would be associated with the final diagnosis (to some extent reflecting the estimated risk already on scene). Furthermore, we hypothesised that sex and age may be influential factors since both may influence the degree of suspicion of AMI (increased suspicion among men and among the elderly).

\section{Study population}

A total of, 3121 EMS missions were carried out in the county catchment area including patients $\geq 18$ years old and with a chief complaint of chest pain (assigned Rapid Emergency Triage and Treatment System (RETTS) code 5, i.e. chest pain, according to PEN on scene [12]). All these missions were eligible for inclusion. After excluding patients declining to participate and patients who were lost to follow-up, 2917 EMS missions remained. Of these, 508 concerned transport from a primary healthcare centre to hospital (Fig. 1). These EMS missions were excluded since in these cases the general practitioner is responsible for patient care during transport and the EMS guidelines do not apply.

Furthermore, 302 and 15 EMS missions respectively were excluded since the patients remained on scene or were transported to a primary healthcare centre (Fig. 1). These cases represent patients for whom the need of care was assessed by the PEN as low or non-existent and also cases in which the patients opposed care.

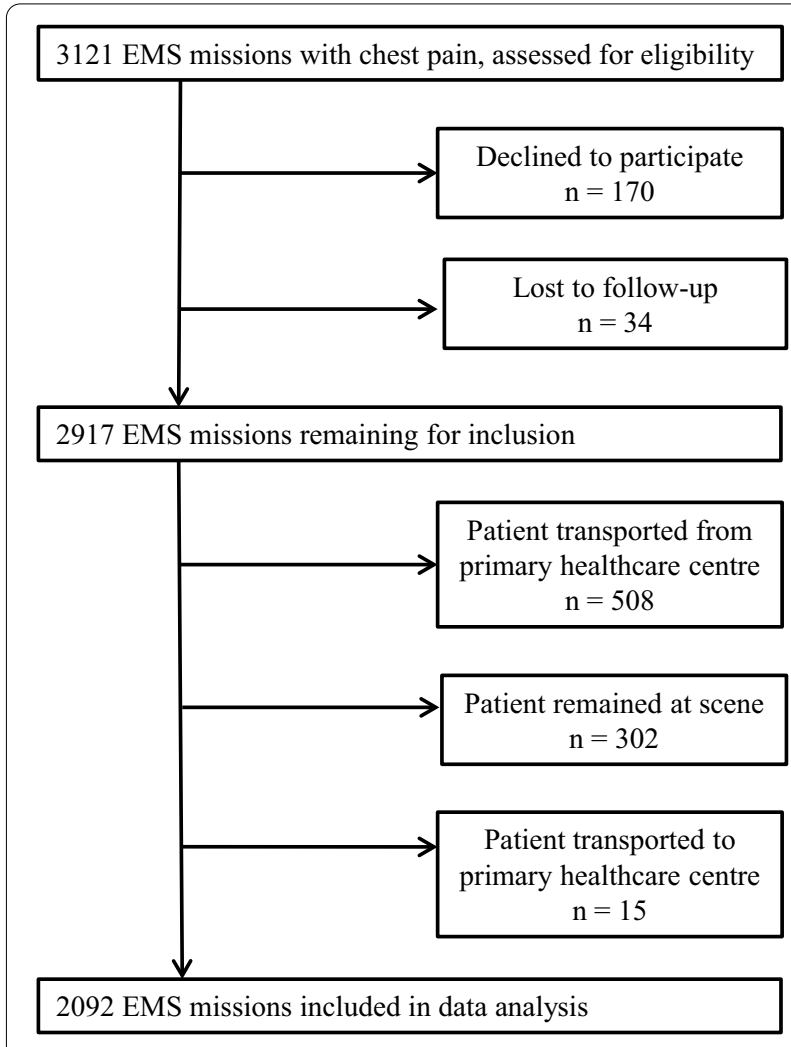

Fig. 1 The number of EMS missions excluded and for what reason 


\section{Clinical setting}

The study was conducted in the county of Halland, Sweden in 2018. Halland has an integrated healthcare system with a catchment area of $5500 \mathrm{~km}^{2}$ and with 329,000 inhabitants in 2018. These are served by two emergency hospitals, including one with percutaneous coronary intervention (PCI) capabilities. There is a single, tax funded, one-tiered EMS organisation with eight ambulance stations and 19 ambulances active during daytime. In 2018, a total of 30,000 missions were carried out by the EMS (inter-hospital site transports excluded).

\section{EMS chest pain guidelines}

In 2018, the EMS guidelines of the county studied stated that all patients with non-traumatic chest pain should be:

- examined using:

- complete vital signs (oxygen saturation, breathing rate, heart rate, systolic blood pressure, level of consciousness and body temperature)

- ECG

- treated with:

- acetylsalicylic acid if pain of suspected cardiac origin

- oxycodone if pain rated $>3$ according to Numeric Rating Scale (NRS)

- sublingual glyceryl trinitrate if pain rated $>3$ according to NRS

- ondansetron if nausea

- oxygen if oxygen saturation $<90 \%$

\section{Data collection}

Each patient was traced throughout the healthcare chain, from EMS mission to hospital discharge. Data on demographics, vital signs, ECG and medical treatment was retrieved from the EMS medical record. Data on symptoms was collected using a novel questionnaire [4] embedded in the EMS medical record. By using electronic tablets, both the questionnaire and the EMS record were available at the bedside during the entire EMS mission. Diagnosis on hospital discharge, according to physician in charge, was retrieved from the hospital medical record.

\section{Endpoint}

Guideline adherence was defined as:

1. complete vital signs

2. ECG registration
Treated with:

3. acetylsalicylic acid

4. oxycodone

5. sublingual glyceryl trinitrate

6. ondansetron

7. oxygen

\section{Statistical analysis}

The results are presented using descriptive statistics including percentage (\%), number of patients $(\mathrm{n})$, median and quartiles where appropriate.

Differences in guideline adherence with respect to patient age, sex and a diagnosis of AMI on hospital discharge were analysed using univariate logistic regression. When analysing the association between age and guideline adherence, the cohort was divided into two groups using median age as cut-off.

Guideline adherence association with patient age, sex or diagnosis of AMI on hospital discharge was thereafter analysed with multivariate logistic regression to provide adjusted results. One multivariate analysis was executed for each of the seven endpoints described above. $P$-values below 0.05 were considered statistically significant. All analyses were carried out using IBM SPSS Statistics 27.

Missing data on ECG, vital signs and pharmaceutical treatment was equated to not being provided as the personnel only registered data on executed tasks. If data was missing on age, sex or diagnosis on hospital discharge the EMS mission was not included in the study. EMS missions with missing data on pain intensity and nausea were excluded from the univariate analyses on treatment with oxycodone and sublingual glyceryl trinitrate respectively ondansetron. For the multivariate analyses data on symptoms were not included and was executed on the complete cohort.

\section{Results}

In total, 2092 EMS missions concerning 1680 unique patients were included. The median age of the cohort was 73 years old (Q25-Q75, 60-83). Sex was evenly distributed. The prevalence of AMI at hospital discharge was $12 \%$. The corresponding figure for male patients were $15 \%$ and for female patients $9 \%$. A majority of the patients rated their pain as three or higher according to NRS. Almost one third of the patients stated they were nauseous. Oxygen saturation below $90 \%$ was present in only three percent of the EMS missions (Table 1).

Guideline adherence was above 90\% regarding ECG registration and complete examination of vital signs, while adherence to pharmaceutical treatment was considerably lower with the exception of oxygen administration. Acetylsalicylic acid was provided in $28 \%$ of all 
Table 1 Description of study sample

\begin{tabular}{|c|c|c|c|c|c|c|}
\hline & \multirow[t]{2}{*}{ All } & \multicolumn{2}{|l|}{ Sex } & \multicolumn{2}{|c|}{ Acute myocardial infarction } & \multirow[t]{2}{*}{ Missing } \\
\hline & & Women & Men & Yes (\%) & No (\%) & \\
\hline All (\%) & $2092(100)$ & $1054(50)$ & $1038(50)$ & $254(12)$ & $1838(88)$ & $0(0)$ \\
\hline \multicolumn{7}{|l|}{ Age } \\
\hline Median (Q25-Q75) & $73(60-83)$ & $74(62-84)$ & $72(58-82)$ & $76(67-85)$ & $73(58-83)$ & $0(0)$ \\
\hline Acute myocardial infarction (\%) & $254(12)$ & $94(9)$ & $160(15)$ & $254(100)$ & $0(0)$ & $0(0)$ \\
\hline NRS > 3 n (\%) & $1234(65)$ & $620(65)$ & $614(65)$ & $160(72)$ & $1074(64)$ & $196(9)$ \\
\hline Nausea (\%) & $540(30)$ & $305(33)$ & $235(26)$ & $63(31)$ & $477(29)$ & $270(13)$ \\
\hline Oxygen saturation < $90 \%(\%)$ & $60(3)$ & $28(3)$ & $32(3)$ & $13(5)$ & $47(3)$ & $4(0.2)$ \\
\hline Priority by emergency dispatch centre & & & & & & $0(0)$ \\
\hline Priority 1 & $1452(69)$ & $717(68)$ & $735(71)$ & $199(78)$ & $1253(68)$ & \\
\hline Priority 2 & $628(30)$ & $328(31)$ & $300(29)$ & $53(21)$ & $575(31)$ & \\
\hline Priority 3 & $12(1)$ & $9(1)$ & $(3(<1)$ & $2(1)$ & $10(1)$ & \\
\hline Priority 4 & $0(0)$ & $0(0)$ & $0(0)$ & $0(0)$ & $0(0)$ & \\
\hline \multicolumn{7}{|l|}{ Priority by EMS-personnel } \\
\hline Priority 1 & $242(12)$ & $81(8)$ & $161(16)$ & $98(39)$ & $144(8)$ & $0(0)$ \\
\hline Priority 2 & $1606(77)$ & $824(78)$ & $782(75)$ & $142(56)$ & $1464(80)$ & \\
\hline Priority 3 & $238(11)$ & $145(14)$ & $93(9)$ & $14(6)$ & $224(12)$ & \\
\hline Priority 4 & $6(<1)$ & $4(<1)$ & $2(<1)$ & $0(0)$ & $6(<1)$ & \\
\hline Median EMS time with patient (min) (Q1-Q3) & $50(44-65)$ & $52(34-68)$ & $50(35-63)$ & $52(48-68)$ & $50(33-65)$ & $27(1)$ \\
\hline
\end{tabular}

Description of the complete cohort of 2092 patients

NRS, Numeric Rating Scale, EMS, Emergency Medical Services

patients and to $50 \%$ of patients with AMI. For patients with pain $>3$ according to NRS 53 percent were treated with sublingual glyceryl trinitrate and $39 \%$ with oxycodone (Table 2).

When adjusting for sex and AMI older patients more commonly had all their vital signs examined compared to younger patients (odds ratio (OR) 1.5). They were also more often given oxygen (OR 2.0) while treatment with ondansetron was rarer (OR 0.72) (Table 3).

Male patients, when adjusting for age and AMI, were less likely to have an ECG registered than female patients (OR 0.55). Both acetylsalicylic acid (OR 1.4) and oxycodone (OR 1.4) were significantly more often administered to men than to women (Table 3).

A diagnosis of AMI on hospital discharge was associated with higher rates of pharmaceutical treatment when adjusting for sex and age. This accounts for all drugs stated in the EMS guidelines and especially when it comes to acetylsalicylic acid (OR 2.9). AMI on hospital discharge did not affect the probability of ECG registration or complete examination of vital signs (Table 3).

The probability of the PEN providing medical treatment was mainly associated with diagnosis of AMI as visualised in Fig. 2. Patient characteristics in terms of age and sex only had little impact on the probability of the PEN measuring vital signs and registering ECG. Sex was associated with the probability of pharmaceutical treatment with women having a lowered probability compared to men (Fig. 2).

\section{Discussion}

This study shows that ECG registration and examination of vital signs were carried out to a large extent by PENs when caring for patients with chest pain. On the other hand, guideline adherence was fairly low in terms of pharmaceutical treatment. This is in line with previous studies investigating guideline adherence among EMS personnel, both PENs and paramedics [7-10]. As hypothesised, improved guideline adherence was associated with a final diagnosis of AMI along with male sex. However, association with patient sex remained also after adjusting for final diagnosis of AMI which was not expected. In the adjusted analyses, old age was associated with improved guideline adherence in terms vital signs and treatment with oxygen, but older patients received ondansetron to a lesser extent.

The lack of guideline adherence in terms of medication administration can probably to some extent be explained by medication contraindications, lack of time when caring for severely ill patients during short transport times or patient refusal. However, previous research states that contraindications are rare [13]. Furthermore, only $12 \%$ of EMS missions included were transported with the highest priority to hospital with 


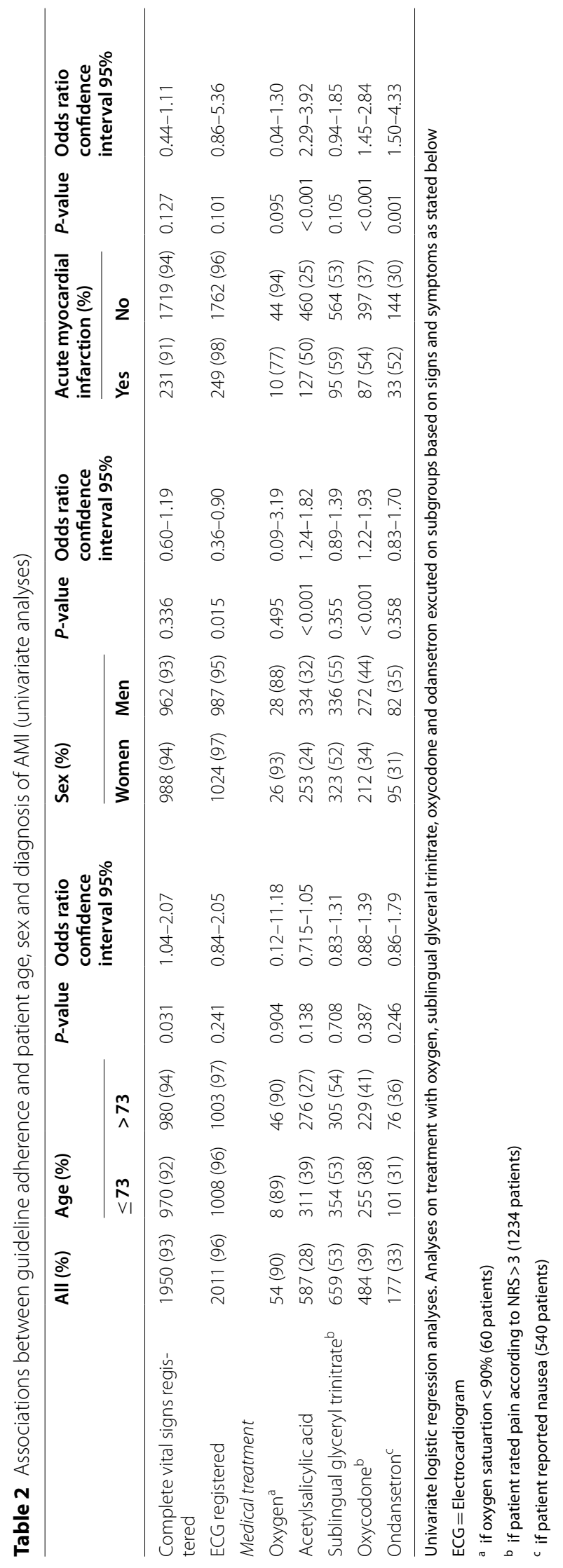


Table 3 Assocations between guideline adherence and patient age, sex and diagnosis of AMI (multivariate analyses)

\begin{tabular}{|c|c|c|c|c|c|c|c|c|c|}
\hline & \multicolumn{3}{|l|}{ Age $>73$} & \multicolumn{3}{|l|}{ Male sex } & \multicolumn{3}{|c|}{ Acute myocardial infarction } \\
\hline & $P$-value & Odds ratio & $\begin{array}{l}\text { Confidence } \\
\text { interval, } \\
95 \%\end{array}$ & $P$-value & Odds ratio & $\begin{array}{l}\text { Confidence } \\
\text { interval, } \\
95 \%\end{array}$ & $P$-value & Odds ratio & $\begin{array}{l}\text { Confidence } \\
\text { interval, } \\
95 \%\end{array}$ \\
\hline Complete vital signs registered & 0.026 & 1.49 & $1.05-2.11$ & 0.504 & 0.89 & $0.63-1.26$ & 0.105 & 0.68 & $0.42-1.09$ \\
\hline ECG registered & 0.358 & 1.24 & $0.79-1.94$ & 0.011 & 0.55 & $0.35-0.87$ & 0.076 & 2.30 & $0.92-5.76$ \\
\hline \multicolumn{10}{|l|}{ Medical treatment } \\
\hline Oxygen & $<0.001$ & 2.05 & $1.62-2.60$ & 0.461 & 1.09 & $0.57-1.37$ & $<0.001$ & 2.22 & $1.64-2.99$ \\
\hline Acetylsalicylic acid & 0.052 & 0.82 & $0.68-1.00$ & 0.001 & 1.39 & $1.14-1.69$ & $<0.001$ & 2.94 & $2.24-3.86$ \\
\hline Sublingual glyceryl trinitrate & 0.429 & 0.93 & $0.78-1.11$ & 0.839 & 0.98 & $0.82-1.17$ & $<0.001$ & 1.65 & $1.27-2.16$ \\
\hline Oxycodone & 0.411 & 0.92 & $0.76-1.12$ & 0.001 & 1.40 & $1.14-1.70$ & $<0.001$ & 2.12 & $1.61-2.78$ \\
\hline Ondansetron & 0.016 & 0.72 & $0.55-0.94$ & 0.253 & 0.86 & $0.66-1.12$ & $<0.001$ & 2.42 & $1.73-3.40$ \\
\hline
\end{tabular}

Multivariate logistic regression analyses including age, sex and diagnosis of AMI onhospital discharge. Analyses excuted on the complete cohort, one analysis for each of theseven guideline objects

ECG Electrocadiogram

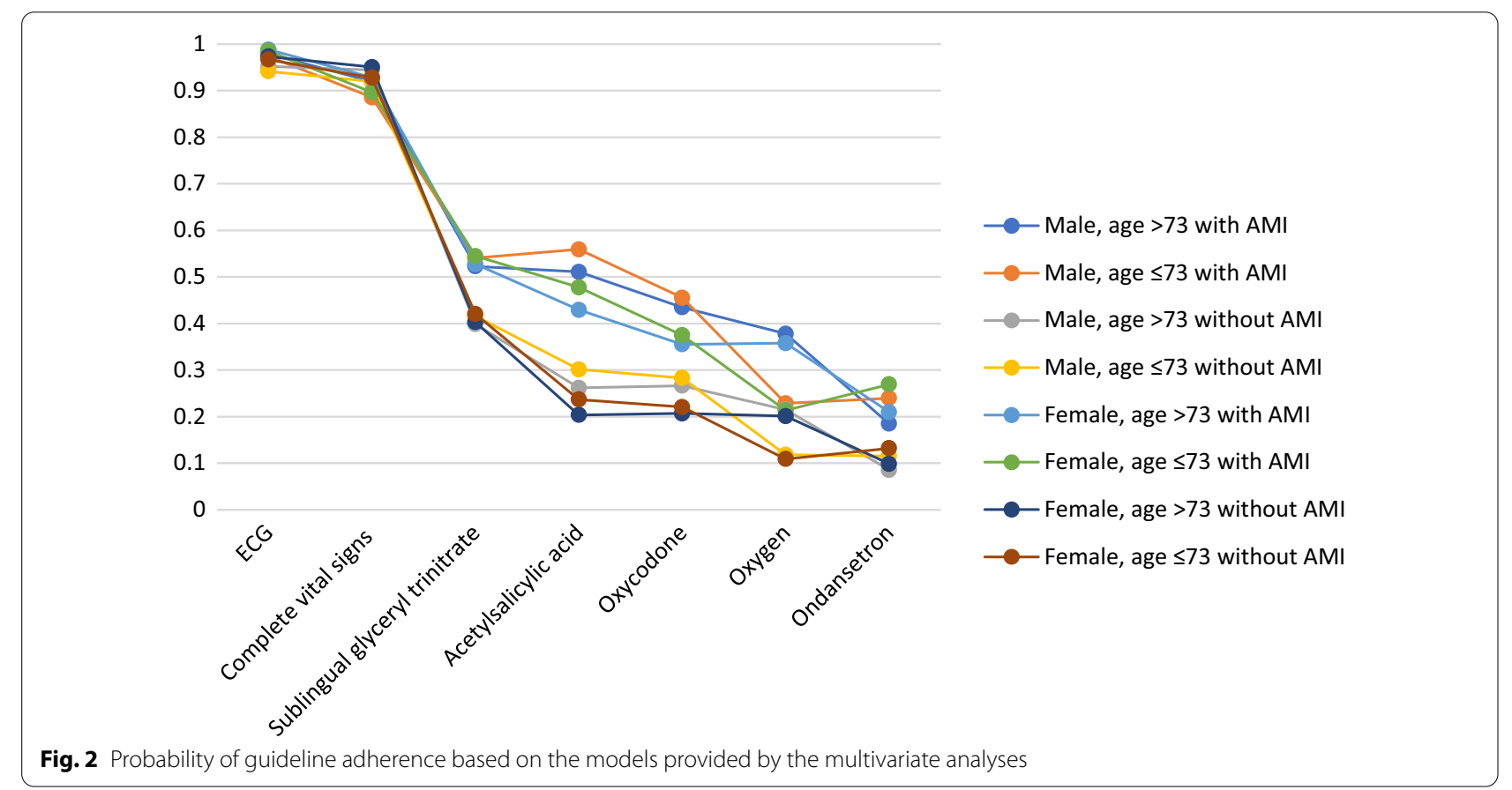

a median patient care time of $50 \mathrm{~min}$ (Table 1). This indicate that rapid patient transport with lights and sirens was rarely needed according to the PEN and that time was not a limiting factor for drug administration in most cases. In addition, patients who refuse medication are also likely to refuse conveyance and these cases were excluded from the study. We may therefore conclude that the situations described are rare and are therefore not the main reasons for omitting to administer the recommended drugs. These situations do not explain either why adherence varies above all with a diagnosis of AMI on hospital discharge, but also in relation to patient sex and age.

Finding that patients with AMI to a larger extent receive medication in line with guidelines indicates that PENs improve their adherence when they suspect the chest pain being of acute cardiac origin. This is also in line with previous results $[9,11]$. In one way this is a positive result since it indicates that PENs to some degree manage to distinguish those with AMI as opposed to those with other origins of their chest pain. However, this approach of basing medical treatment on PENs suspicion 
of AMI results in $50 \%$ of the patients with AMI ending up without prehospital medication with acetylsalicylic acid. This may be particularly problematic since early treatment with acetylsalicylic acid when suffering from AMI has been reported to decrease mortality rates [5]. We suggest altering the guidelines to support medication with acetylsalicylic acid also when suspicion of ACS is low to increase the proportion of patients with AMI provided acetylsalicylic acid already by the EMS.

In our study women are less likely than men to receive treatment with acetylsalicylic acid and oxycodone. These differences are at hand both in the univariate analyses and multivariate ones adjusting for age and diagnosis of AMI on hospital discharge. The difference can thereby not be explained by neither the higher median age nor the lower incidence of AMI among women but rather by sex itself. This is problematic as it indicates an inequality in EMS care of patients with chest pain based on sex. Sex inequalities in AMI care has been shown in previous in-hospital research [14-16] and also regarding direct admission to PCI [17] and time to acetylsalicylic acid treatment [18]. But, to the best of our knowledge, it has not previously been reported that women with chest pain are less likely than men to receive pharmaceutical treatment already in the prehospital phase. The occurrence of sex differences in prehospital chest pain care should be investigated further along with research on why such differences exists.

An ECG was registered in $96 \%$ of all cases. Thus this is the part of the guidelines with the highest adherence among PENs. Previous research shows an association between underuse of ECG and increased mortality [19]. The high adherence is a positive finding and this should benefit the patient.

A guideline adherence of $100 \%$ is neither possible nor desirable given the multifaceted setting in which prehospital emergency care takes place. Patient characteristics, lack of time, limited personnel resources and technical errors are all acceptable reasons why adherence to guidelines is not always possible. However, in most cases, the conditions do not prohibit guideline adherence and improved compliance should be possible. Two easily accessible ways to achieve this may be firstly to advocate a more generous approach regarding both examination and pharmaceutical treatment, and secondly that the guidelines should apply also in cases in which PENs judge the probability of cardiac origin to be low. Improving both EMS and the emergency dispatch centre personnel ability to identify patients with AMI by the use of risk assessment tools $[20,21]$ and/or introducing prehospital troponin [21-24] could also be ways to enhance the prehospital care of patients with chest pain, not only in terms of guideline adherence. Improved adherence may also possibly be achieved by using interactive tools that suggest appropriate examination and treatment based on the data the EMS personnel feed into the tools [25]. Furthermore, education of EMS personnel on the difficulties of ruling out AMI in the EMS setting, along with structured follow-up of in-hospital patient care, could give rise to new insights and maybe a more generous approach when caring for patients with chest pain. Studies on how to improve guideline adherence among EMS personnel are warranted.

\section{Strengths and limitations}

This study is strengthened by the unselected inclusion of EMS missions comprising an almost complete population of EMS chest pain patients during one year. It investigates guideline adherence both in terms of patient examinations and various medical treatments and how this is associated with diagnosis on discharge which, to our knowledge, has not been studied before in the prehospital context.

One limitation is that the multivariate analyses do not take into account whether the medical treatment provided was called for or not in terms of presence of nausea, desaturation or pain rated higher than three according to NRS. These aspects were only considered in the univariate analyses. This distinction was necessary to achieve statistical viability but complicates comparison between the uni- and multivariate analyses. Such "over treatment" can be considered a breach of the guidelines. However, the drugs included in the current guidelines are not very potent and "over treatment" is therefore quite unproblematic. For example studies has shown that short term "over treatment" with oxygen do not affect patient outcome [26]. Furthermore, prehospital treatment with acetylsalicylic acid [27] or sublingual glyceryl trinitrate [28] are rarely associated with adverse events. In addition, the identified associations between guideline adherence and age, sex and AMI are of interest regardless of if "over treatment" is at hand or not.

This study is partly based on data retrieved from the EMS records. It is possible that PENs sometimes failed to document examinations carried out and medication administered. Thus guideline adherence may actually be better than can be inferred from available data. The prevalence of such documentation error is unknown. Documentation in the EMS record was possible both bedside and during transport by using tablets, as well as after completed mission by computers at the emergency department and the EMS stations. Furthermore, PENs are obliged by Swedish law to document which examinations they carry out and which medication they administer. It is therefore assumed that such documentation errors are rare and do not affect the results to any 
significant extent. There is also a risk that the PENs register tasks that were not actually performed or improved their guideline adherence since the PENs were aware that data from the EMS record was to be used in the current study. Guideline adherence may, thereby, also be lower than the results indicate. It is difficult to assess if, and if so, to what extent this is at hand, but the risk should not be neglected. Both missed registrations and registering tasks that were not executed affects the internal validity negatively.

This study only considers patient related factors when analysing association with guideline adherence. However, guideline adherence is probably associated with several other, non-patient, factors such as education and experience of the PEN, time of the day, workload and distance to hospital. It was not within the scope of this study to investigate such factors, but one should be aware that other variables than the ones studied may influence guideline adherence. This negatively affect the external validity and should be considered when applying the results on other EMS organisations and settings with other prerequisites regarding for example EMS personnel education or EMS funding. The findings of this study primarily apply to EMS organisations with PENs staffing the ambulances. As the findings, in terms of adherence to pharmaceutical treatment guidelines, confirm the findings from previous studies [7-10] on both nurse and paramedic guideline adherence it is reasonable to assume that EMS personnel education level is not crucial for guideline adherence. Furthermore, the nearly complete and unselected inclusion of all EMS missions within the county concerning patients with chest pain during 2018 and data being provided by close to 200 different PENs increases the generalisability of the results.

In this study the same patient could be included several times if cared for by the EMS on multiple occasions during the inclusion period (2092 EMS missions concerning 1680 unique patients). Therefore, one can argue that included EMS missions are not independent events. However, caring for the same patient on multiple occasions reflect the reality of EMS care and guidelines do not state that patients should be cared for differently based on the quantity of EMS missions. Furthermore, there are close to 200 PENs working in the current county. This lowers the probability for same PEN caring for the same patient on multiple occasions. We therefore judged it appropriate not to exclude patients based on number of EMS contacts.

\section{Conclusions}

Guideline adherence among PENs when caring for patients with chest pain is satisfactory in regarding registration of vital signs and ECG. Guideline adherence among PENs, in terms of medical treatment, is defective. Adherence is better in cases in which patients are diagnosed with AMI on hospital discharge. This indicates that PENs' assessments of patients' conditions affect which medications patients receive, which is positive. However, this results in only $50 \%$ of the patients diagnosed with AMI on hospital discharge receiving acetylsalicylic acid in the prehospital setting. Improved adherence is associated with higher age and male sex indicating age, but above all, gender inequalities in EMS care of patients with chest pain.

\section{Abbreviations \\ AMI: Acute myocardial infarction; ECG: Electrocardiogram; EMS: Emergency medical services; NRS: Numeric rating scale; OR: Odds ratio; PCI: Percutaneous coronary intervention; PEN: Prehospital emergency nurse.}

\section{Acknowledgements}

We want to thank the following persons: Margaret Myers for language editing. The EMS personnel of Region Halland for their participation in the study.

\section{Authors' contributions}

$\mathrm{KW}, \mathrm{ML}, J \mathrm{H}, \mathrm{LB}$, SO and $\mathrm{AB}$ planned the data collection. KW, LB and $\mathrm{SO}$ designed the study. KW, LB and SO carried out data analysis. KW, ML, JH, LB, SO and $A B$ contributed to writing the manuscript. All authors read and approved the final manuscript.

\section{Funding}

Open access funding provided by University of Gothenburg. This study has been funded by the Department of Ambulance and Prehospital Care, Region Halland, and the Scientific Council of Region Halland (HALLAND-209901). The funding bodies had no role in the design, conduct, interpretation or writing of the report on this research.

\section{Availability of data and materials}

The datasets generated and analysed during the current study are not publicly available due the integrity of patient privacy but are available from the corresponding author on reasonable request and if approved by the Regional Ethical Review Board in Lund.

\section{Declarations}

\section{Ethics approval and consent to participate}

In this study, all patients eligible for inclusion were subject to an opt-out procedure. The study was approved by the Regional Ethical Review Board in Lund (Dno 2017/212).

\section{Consent for publication}

Not applicable.

\section{Competing interests}

The authors declare that they have no competing interests.

\section{Author details}

${ }^{1}$ Department of Ambulance and Prehospital Care, Region Halland, Varlabergsvägen 29, 43439 Kungsbacka, Sweden. ${ }^{2}$ Institute of Health and Care Sciences, Sahlgrenska Academy, University of Gothenburg, Göteborg, Sweden. ${ }^{3}$ Department of Molecular and Clinical Medicine/Cardiology, Institute of Medicine, Sahlgrenska Academy, University of Gothenburg, Göteborg, Sweden. ${ }^{4}$ Department of Development, Halland Hospital, Halmstad, Sweden. ${ }^{5}$ The Prehospital Research Center Western Sweden, University of Borås, Borås, Sweden. ${ }^{6}$ Department of Emergency Care, Södra Älvsborgs Hospital, Region Västra Götaland, Sweden. 
Received: 7 June 2021 Accepted: 25 October 2021

Published online: 30 October 2021

\section{References}

1. Clawson J, Olola C, Heward A, Patterson B, Scott G. The Medical Priority Dispatch System's ability to predict cardiac arrest outcomes and high acuity pre-hospital alerts in chest pain patients presenting to 9-9-9. Resuscitation. 2008;78(3):298-306.

2. Pedersen CK, Stengaard C, Friesgaard K, Dodt KK, Søndergaard HM, Terkelsen CJ, et al. Chest pain in the ambulance; prevalence, causes and outcome-a retrospective cohort study. Scand J Trauma Resusc Emerg Med. 2019;27(1):84.

3. Rawshani A, Larsson A, Gelang C, Lindqvist J, Gellerstedt M, Bang A, et al. Characteristics and outcome among patients who dial for the EMS due to chest pain. Int J Cardiol. 2014;176(3):859-65.

4. Wibring K, Lingman M, Herlitz J, Amin S, Bång A. Prehospital stratification in acute chest pain patient into high risk and low risk by emergency medical service: a prospective cohort study. BMJ Open. 2021;11(4):e044938

5. Savino PB, Sporer KA, Barger JA, Brown JF, Gilbert GH, Koenig KL, et al. Chest pain of suspected cardiac origin: current evidence-based recommendations for prehospital care. West J Emerg Med. 2015;16(7):983-95.

6. Beygui F, Castren M, Brunetti ND, Rosell-Ortiz F, Christ M, Zeymer U, et al Pre-hospital management of patients with chest pain and/or dyspnoea of cardiac origin. A position paper of the Acute Cardiovascular Care Association (ACCA) of the ESC. Eur Heart J Acute Cardiovasc Care. 2015.

7. Francis RC, Bubser F, Schmidbauer W, Spies CD, Sörensen M, Bosse G, et al. Effects of a standard operating procedure on prehospital emergency care of patients presenting with symptoms of the acute coronary syndrome. Eur J Emerg Med. 2014;21(3):236-9.

8. Woollard M, Smith A, Elwood P. Pre-hospital aspirin for suspected myocardial infarction and acute coronary syndromes: a headache for paramedics? Emerg Med J. 2001:18(6):478-81.

9. Strandmark R, Herlitz J, Axelsson C, Claesson A, Bremer A, Karlsson T, et al. Determinants of pre-hospital pharmacological intervention and its association with outcome in acute myocardial infarction. Scand J Trauma Resusc Emerg Med. 2015;23:105

10. MCVaney KE, Macht M, Colwell CB, Pons PT. Treatment of suspected cardiac ischemia with aspirin by paramedics in an urban emergency medical services system. Prehosp Emerg Care. 2005;9(3):282-4.

11. Hooker EA, Benoit T, Price TG. Reasons prehospital personnel do not administer aspirin to all patients complaining of chest pain. Prehosp Disaster Med. 2006;21(2):101-3.

12. Magnusson C, Herlitz J, Axelsson C. Patient characteristics, triage utilisation, level of care, and outcomes in an unselected adult patient population seen by the emergency medical services: a prospective observational study. BMC Emerg Med. 2020;20(1):7.

13. Byrsell F, Regnell M, Johansson A. Adherence to treatment guidelines for patients with chest pain varies in a nurse-led prehospital ambulance system. Int Emerg Nurs. 2012;20(3):162-6.

14. Fogg AJ, Welsh J, Banks E, Abhayaratna W, Korda RJ. Variation in cardiovascular disease care: an Australian cohort study on sex differences in receipt of coronary procedures. BMJ Open. 2019;9(7):e026507.
15. Rashid S, Simms A, Batin P, Kurian J, Gale CP. Inequalities in care in patients with acute myocardial infarction. World J Cardiol. 2015;7(12):895-901.

16. Gnavi R, Rusciani R, Dalmasso M, Giammaria M, Anselmino M, Roggeri $D P$, et al. Gender, socioeconomic position, revascularization procedures and mortality in patients presenting with STEMI and NSTEMI in the era of primary PCI. Differences or inequities? Int J Cardiol. 2014;176(3):724-30.

17. Ravn-Fischer A, Caidahl K, Hartford M, Karlsson T, Kihlgren S, Perers E, et al. Community-based gender perspectives of triage and treatment in suspected myocardial infarction. Int J Cardiol. 2012;156(2):139-43.

18. Ravn-Fischer A, Karlsson T, Santos M, Bergman B, Herlitz J, Johanson P. Inequalities in the early treatment of women and men with acute chest pain? Am J Emerg Med. 2012;30(8):1515-21.

19. Rawshani N, Rawshani A, Gelang C, Herlitz J, Bång A, Andersson JO, et al. Association between use of pre-hospital ECG and 30-day mortality: a large cohort study of patients experiencing chest pain. Int J Cardiol. 2017:248:77-81.

20. Gellerstedt M, Rawshani N, Herlitz J, Bång A, Gelang C, Andersson $\mathrm{JO}$, et al. Could prioritisation by emergency medicine dispatchers be improved by using computer-based decision support? A cohort of patients with chest pain. Int J Cardiol. 2016:220:734-8.

21. van Dongen DN, Tolsma RT, Fokkert MJ, Badings EA, van der Sluis A, Slingerland RJ, et al. Pre-hospital risk assessment in suspected non-STelevation acute coronary syndrome: A prospective observational study. Eur Heart J Acute Cardiovasc Care. 2020;9(1_suppl):5-12.

22. Stopyra JP, Harper WS, Higgins TJ, Prokesova JV, Winslow JE, Nelson RD, et al. Prehospital modified HEART score predICTive of 30-day adverse cardiac events. Prehosp Disaster Med. 2018;33(1):58-62.

23. Cooper JG, Ferguson J, Donaldson LA, Black KMM, Livock KJ, Horrill JL, et al. The Ambulance Cardiac Chest Pain Evaluation in Scotland Study (ACCESS): a prospective cohort study. Ann Emerg Med. 2021.

24. Stengaard C, Sørensen JT, Rasmussen MB, Søndergaard HM, Dodt KK, Niemann T, et al. Editor's choice-acute versus subacute angiography in patients with non-ST-elevation myocardial infarction-the NONSTEMI trial phase I. Eur Heart J Acute Cardiovasc Care. 2017;6(6):490-9.

25. Hagiwara MA, Sjöqvist BA, Lundberg L, Suserud BO, Henricson M, Jonsson A. Decision support system in prehospital care: a randomized controlled simulation study. Am J Emerg Med. 2013;31(1):145-53.

26. Hofmann R, Befekadu Abebe T, Herlitz J, James SK, Erlinge D, Yndigegn $\mathrm{T}$, et al. Routine oxygen therapy does not improve health-related quality of life in patients with acute myocardial infarction-insights from the randomized DETO2X-AMI trial. Front Cardiovasc Med. 2021;8:638829.

27. Ouan D, LoVecchio F, Clark B, Gallagher JV. Prehospital use of aspirin rarely is associated with adverse events. Prehosp Disaster Med. 2004;19(4):362-5.

28. Popp LM, Lowell LM, Ashburn NP, Stopyra JP. Adverse events after prehospital nitroglycerin administration in a nationwide registry analysis. Am J Emerg Med. 2021;50:196-201.

\section{Publisher's Note}

Springer Nature remains neutral with regard to jurisdictional claims in published maps and institutional affiliations.

Ready to submit your research? Choose BMC and benefit from

- fast, convenient online submission

- thorough peer review by experienced researchers in your field

- rapid publication on acceptance

- support for research data, including large and complex data types

- gold Open Access which fosters wider collaboration and increased citations

- maximum visibility for your research: over 100M website views per year

At BMC, research is always in progress.

Learn more biomedcentral.com/submissions 